\title{
Application of neural network model in construction quality evaluation of core wall rockfill dam
}

\author{
Wang Qianwei ${ }^{1, \text { a }}$, Zhong Denghua ${ }^{1, b}$, Zhao Jianghao ${ }^{1, c}$ \\ ${ }^{1}$ State Key Laboratory of Hydraulic Engineering Simulation and Safety, Tianjin University, 92Weijin \\ Road, Nankai District, Tianjin 300072, China \\ atjuwangqw@126.com; bdzhong@tju.edu.cn; 'zhaojianghao123@163.com
}

\begin{abstract}
Keywords: High core rockfill dam, Neural network model, Rolling construction, Construction quality evaluation.

Abstract. At present, high core rockfill dam mainly uses the real-time monitoring system to control the roller compacted construction quality, and the quality of roller compacted construction unit was evaluated by the test pit experiment. However, in the course of the experiment, the filling body of the experimental points need to be excavated, so that the filling body has a larger disturbance. This will affect the results of the experiment. At the same time, test pit experiments need to continue for a long time, however, only after the quality inspection results qualified, the follow-up construction can be carried out after, which affect the subsequent construction. In order to effectively solve the above problems, this paper established the quality evaluation index system and model of rockfill dam construction by using neural network method, and trained and tested the model with actual data. The test results show that the model has a good evaluation accuracy, and it is of great practical significance to improve the accuracy and timeliness of the core wall rockfill dam construction quality evaluation.
\end{abstract}

\section{Introduction}

With the development of China's water conservancy and hydropower engineering construction, the dam height of the core wall rockfill dam began to be developed and built at the $300 \mathrm{~m}$ level. The improvement of the construction scale of the core wall rockfill dam brings new challenges to the safety of the dam, and puts forward higher requirements for the construction and management of the dam, especially the construction quality contro[ ${ }^{[1]}$. Construction quality control of rockfill dam is the main link of construction quality control of rockfill dam, and the quality of dam construction is mainly related to the quality of dam and the quality of roller compacted ${ }^{[2]}$. At present, high core rockfill dam mainly uses the real-time monitoring system to control the roller compacted construction quality, and the quality of roller compacted construction unit was evaluated by the test pit experiment. However, in the course of the experiment, the filling body of the experimental points need to be excavated, so that the filling body has a larger disturbance. This will affect the results of the experiment. At the same time, test pit experiments need to continue for a long time, however, only after the quality inspection results qualified, the follow-up construction can be carried out after, which affect the subsequent construction. Therefore, it can be considered to combine real-time monitoring data with quality inspection results of soil stone, use a certain algorithm to calculate the construction quality evaluation results. Compaction process has many influential factors, and it has strong randomness and fuzziness. The artificial neural network is easy to model, calculate or reason for the complex nonlinear object which is difficult to describe accurately, so it can be used to evaluate the quality of roller compacted construction by using the artificial neural network model. This paper analyzes the influence factors of the construction quality of the core wall rockfill dam, and establishes the evaluation index system of the construction quality of the core wall rockfill dam. And with the gravel soil P5 content, water content, the number of compaction times, compaction thickness for the input layer, the construction quality of the construction unit for the output layer, it establishes the neural network model. The network model is trained and tested by the actual data in the field. The test results show that the model can be well used in the evaluation of the quality of dam construction 
process. It has very important practical significance to improve the accuracy of the evaluation of the core wall rockfill dam construction quality and to speed up the construction progress.

\section{Construction quality evaluation index system of core wall rockfill dam}

The construction quality of rockfill dam is mainly related to the quality of the dam and the quality of roller compacted rockfill dam. The main control parameters of gravel soil quality are P5 content (Percentage of particles larger than $5 \mathrm{~mm}$ in soil) and water content, and the roller compacted quality can be determined by the ratio of the number of compaction times (the percentage account between the area of which the number of roller compacted up to the standard times and above and the whole construction unit area in the construction unit) and the thickness of compaction. The above indicators were expressed by $\mathrm{U}_{1}, \mathrm{U}_{2}, \mathrm{U}_{3}, \mathrm{U}_{4}$, specific see figure 1 .

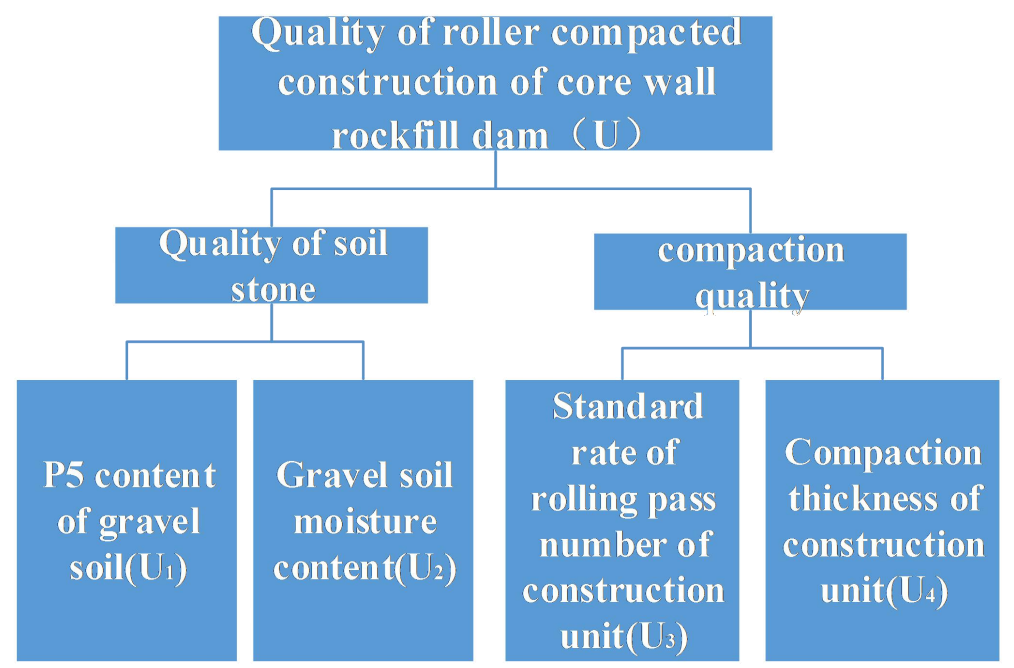

Fig.1 Quality evaluation system for roller compacted construction of core wall rockfill dam

\section{Neural network model establishment}

Artificial neural network is a new information processing science, it has a strong non-linear, large-scale parallel processing capabilities, has a wide range of application prospects. It has distributed storage, parallel processing and adaptive learning, can directly use the sample data to realize nonlinear mapping between input and output layer, and does not need to set up a calculation equation, is very suitable for difficult to model but easy to collect learning sample questions. It can make a reasonable judgment decision of complex problems and deal with the problem according to the knowledge learned experience, give a satisfactory answer, or make the effective forecast and the estimate of the future without the artificial weight ${ }^{[3]}$.

BP network is composed of 3 layers of neurons, the bottom layer is the input layer, the middle layer is the hidden layer and the top layer called the output layer. The interconnection between the various levels are neurons, no connections between neurons in each layer, as shown in figure 2 . 


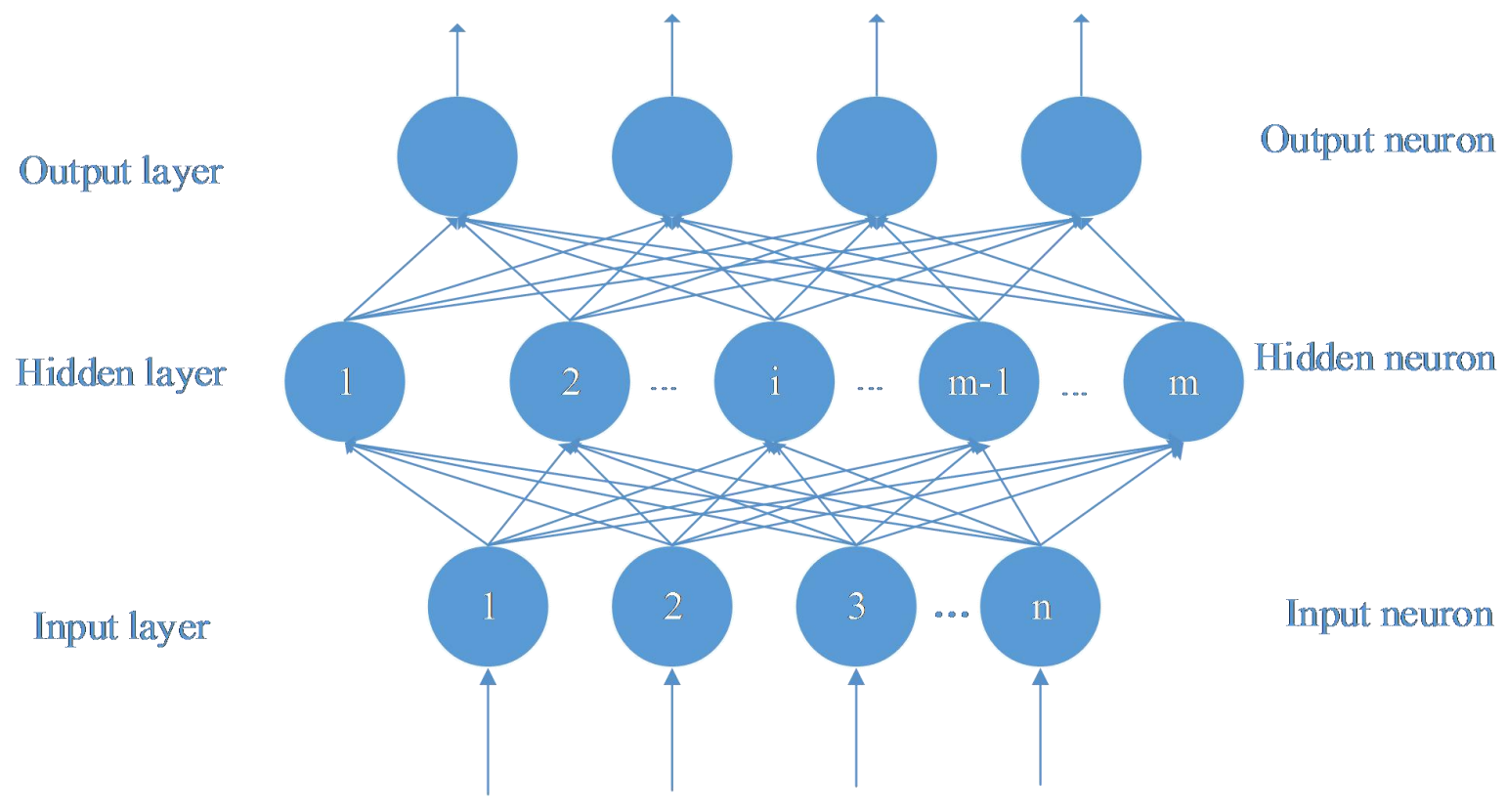

Fig.2 Structure of artificial neural network model

\section{Input nodes determination}

According to the construction quality evaluation index system of the core wall rockfill dam built in this paper, 4 indexes of $U_{1}, U_{2}, U_{3}$ and $U_{4}$ as the 4 nodes of the network input layer are evaluated. Because the qualitative analysis is used in this paper, it is necessary to quantify the indicators in order to facilitate the application of the network model when the input node is input.

\section{Hidden layer nodes determination}

If the unit number of input layer, hidden layer and output layer are respectively n, $q, m$, the three layer network can be expressed as BP (n, q, m), which can realize the nonlinear mapping of $\mathrm{n}$-dimensional input vector $U_{n}=\left(U_{1} \ldots U_{n}\right)^{T}$ to $m$-dimensional output vector $Y_{m}=\left(Y 1 \ldots Y_{m}\right)^{T}$ by the network. To measure and affect the core wall rockfill dam construction quality of the 4 main indicators as the input, that is, the neuron $n=4$, the evaluation results as the output of the network, so $m=1$. But there is no mature method to determine the number of $Q$ in the hidden layer unit. In practice, it can be determined by the formula $\mathrm{q}=\log 2 \mathrm{n}$. The number of hidden layer nodes in this model is selected as 2 .

\section{Output nodes determination}

The output node is selected to correspond to the evaluation results. In this model, the final result is the evaluation of the construction quality of roller compacted rockfill dam, the output layer is excellent, good, qualified 3 grades, respectively, 1 corresponding to "excellent", 2 ,"good", and 3 ,"qualified".

\section{BP neural network algorithm selection}

The learning process of BP neural network is composed of two parts: forward propagation and reverse propagation, and the algorithm is described as follows.

(1)Initialization weights and thresholds. After the network structure BP (n, Q, m) is determined, the network parameters include the weight $W_{i j}^{1}(\mathrm{i}=1, \cdots, \mathrm{n} ; \mathrm{i}=1, \cdots, \mathrm{q})$ from the input layer $\mathrm{i}$ unit to the hidden layer $\mathrm{j}$ unit , the weight $W_{j k}^{0}(\mathrm{j}=1, \ldots, \mathrm{q} ; \mathrm{k}=1, \ldots, \mathrm{m})$ from the hidden layer $\mathrm{j}$ unit to the output layer $\mathrm{k}$ unit, the activation threshold of the hidden layer $\mathrm{j}$ unit $\theta_{j}^{H}(\mathrm{j}=1, \cdots, \mathrm{q})$ and the activation threshold of the output layer $\mathrm{k}$ unit $\theta_{k}^{0}(\mathrm{k}=1, \cdots, \mathrm{m})$. The initial values of the weights and thresholds are randomly generated prior to network training.

(2) Training sample information. Assuming that there are a total of $\mathrm{P}$ training samples. The information of the training sample $\mathrm{RV}(\mathrm{R}=1, \ldots, \mathrm{P})$ is transmitted to the hidden unit, and the output information of the hidden layer is obtained by the action of the activation function $\mathrm{f}(\mathrm{x})$ : 


$$
H_{j r}=f\left(\sum_{1}^{n} W_{i j}^{1} X_{j r}-\theta_{j}^{H}\right),(\mathrm{j}=1, \ldots, \mathrm{q} ; \mathrm{r}=1, \ldots, \mathrm{p})
$$

The activation function $\mathrm{f}(\mathrm{x})$ generally uses the Sigmoid type, namely

$$
\mathrm{f}(\mathrm{x})=\frac{1}{1+e^{-x}}
$$

The output information of the hidden layer is transmitted to the output layer, and the final output node can be obtained.

$$
Y_{k r}=f\left(\sum_{1}^{q} W_{j k}^{0} H_{j r}-\theta_{k}^{0}\right),(\mathrm{k}=1, \ldots, \mathrm{m} ; \mathrm{r}=1, \ldots, \mathrm{p})
$$

(3) The above process is the forward propagation process of network learning information, and the other process is the error back propagation process. If there is an error between the network output and the desired output, the error back propagation, the use of the formula (4) to adjust the network weights and thresholds:

$$
\Delta w(t+1)=\eta \frac{\partial E}{\partial w} \alpha \Delta w(t)
$$

In the formula, $\Delta \mathrm{w}(\mathrm{t})$ is correction weight values and threshold values of the $t$ training. $\eta$ and $\alpha$ are scale factor and momentum factor. $\mathrm{E}=\frac{1}{2} \sum_{1}^{m} \sum_{1}^{p}\left(Y_{r}-t_{r}\right)^{2}$. Repeating the above two processes until the error between the network output and the expected output is satisfied with the requirement ${ }^{[4]}$.

\section{Engineering application}

An empirical study on 24 construction units of a high core rockfill dam in Southwest China (in order

\begin{tabular}{|c|c|c|c|c|c|c|}
\hline U1 & $\mathbf{U} \mathbf{2}$ & $\mathbf{U 3}$ & U4 & $\begin{array}{c}\text { Expecte } \\
\text { d value }\end{array}$ & Output value & $\begin{array}{c}\text { Evaluation } \\
\text { result }\end{array}$ \\
\hline 0.6 & 0.6 & 1 & 0.8 & 2 & 2.1358 & 良 \\
\hline 1 & 1 & 1 & 0.8 & 1 & 0.9759 & 优 \\
\hline 1 & 1 & 0.8 & 0.8 & 1 & 1.1497 & 优 \\
\hline 0.6 & 1 & 1 & 1 & 1 & 1.3746 & 优 \\
\hline 0.8 & 1 & 1 & 1 & 1 & 1.1021 & 优 \\
\hline 0.6 & 0.8 & 1 & 0.8 & 2 & 2.0113 & 良 \\
\hline 0.6 & 0.6 & 0.6 & 0.8 & 3 & 3.2692 & 合格 \\
\hline 0.6 & 0.6 & 0.6 & 0.6 & 3 & 3.4681 & 合格 \\
\hline 0.6 & 1 & 1 & 0.8 & 1 & 1.4157 & 优 \\
\hline 1 & 0.6 & 1 & 0.8 & 1 & 1.4935 & 优 \\
\hline 0.8 & 0.6 & 1 & 0.8 & 2 & 1.9794 & 良 \\
\hline 0.8 & 0.8 & 0.8 & 0.8 & 2 & 2.0653 & 良 \\
\hline 0.8 & 0.6 & 1 & 1 & 2 & 2.3492 & 良 \\
\hline 0.6 & 0.6 & 0.8 & 0.8 & 3 & 3.0521 & 合格 \\
\hline 0.6 & 0.6 & 1 & 1 & 2 & 2.4037 & 良 \\
\hline 0.6 & 0.8 & 1 & 1 & 2 & 2.3059 & 良 \\
\hline 0.8 & 0.6 & 1 & 0.6 & 3 & 2.9578 & 合格 \\
\hline 0.6 & 0.6 & 1 & 0.8 & 3 & 3.0254 & 合格 \\
\hline 0.6 & 0.6 & 0.6 & 1 & 3 & 3.3273 & 合格 \\
\hline 1 & 0.8 & 0.8 & 0.8 & 2 & 1.5374 & 良 \\
\hline 1 & 1 & 1 & 1 & 1 & 0.9541 & 优 \\
\hline 1 & 0.6 & 1 & 1 & 1 & 0.9958 & 优 \\
\hline 0.8 & 1 & 1 & 0.8 & 1 & 1.1749 & 优 \\
\hline 0.6 & 0.6 & 1 & 0.6 & 3 & 2.9756 & 合格 \\
\hline
\end{tabular}
to facilitate data processing, excellent corresponding to 1 , good corresponding to 0.8 , qualified corresponding to 0.6 ), the specific input and output results see Table 1 .

Tab. 1 quality evaluation results of core wall rock fill dam 


\section{Conclusions}

According to the above analysis, it is known that the neural network can be used to establish the simulation model of the quality evaluation of the roller compacted construction of high core wall rockfill dam. Because the neural network has better nonlinear mapping performance, it has a better performance in the qualitative evaluation. Good simulation function ensures the objectivity of the evaluation results. The research results show that the model is feasible and effective.

\section{Acknowledgements}

This work was financially supported by the Innovative Research Groups of the National Natural Science Foundation of China (Grant No. 51321065), the Natural Science Foundation of China (Grant No. 51439005), the National Basic Research Program of China (973 Program) (2013CB035904).

\section{References}

[1] Wang Bole, Liu Yinzhen, Wu Hehe: New progress of earth rockfill dam construction in China, Hydroelectric power, Vol 31(1). 63-65 (2005).

[2] Cui Bo: Integrated theory and application of real time monitoring system for construction quality of core wall rockfill dam, Doctoral Dissertation of Tianjin University, (2009).

[3] Zheng Shaoying, Chen Jinru: Application Research on quality evaluation of reinforced concrete construction based on artificial neural network, Building Science Research of Sichuan, Vol 35(6).301-303 (2009).

[4] Zheng Shaoying, Zhou Dongming, Xu Tinghua, Chen Jinru : Application of artificial neural network in the evaluation of concrete construction quality, Concrete, Vol 4.120-122 (2008). 